\title{
DEVELOPMENT OF A COMBUSTION SYSTEM FOR LIQUID OR GAS SAMPLES
}

\author{
J H Park • C S Lee ${ }^{1}$ \\ Department of Physics, Chung-Ang University, Seoul 156-756, South Korea.
}

\begin{abstract}
While it is customary to use solid samples for measuring the ${ }^{14} \mathrm{C} /{ }^{12} \mathrm{C}$ ratio, it is sometimes necessary to handle liquid or gas samples. Motivated by a scientific purpose to count radiocarbon yields in deuterated acetone irradiated with energetic neutrons, we developed a new combustion system to treat liquid or gas samples. In contrast with the typical combustion system using $\mathrm{CuO}$ for solid samples, the new combustion system uses high-purity $\mathrm{O}_{2}(99.999 \%)$ gas. As an initial investigation, we combusted deuterated acetone (acetone- $\mathrm{d}_{6}$, certified $100.0 \mathrm{~atm} \% \mathrm{D}$ ) to make $\mathrm{CO}_{2}$ under the ambient $\mathrm{O}_{2}$ pressure. The resulting $\mathrm{CO}_{2}$ gas then went through the reduction process to form graphite for further accelerator mass spectrometry (AMS) measurement.
\end{abstract}

\section{INTRODUCTION}

In March 2002, Taleyarkhan et al. reported an interesting result in cavitation experiments using deuterated acetone (acetone- $\mathrm{d}_{6}$, certified $100.0 \mathrm{~atm} \% \mathrm{D}$ ) bombarded by $14-\mathrm{MeV}$ neutrons: that tritium $\beta$-decay activity above background levels was detected and $2.5-\mathrm{MeV}$ neutrons were also observed as would be expected for deuterium-deuterium (DD) fusion (Taleyarkhan et al. 2002). However, in a subsequent experiment using the same cavitation apparatus, Shapira et al. (2002) found no evidence for $2.5-\mathrm{MeV}$ neutron emission correlated with sonoluminescence (SL), in which light is emitted from collapsing bubbles in a liquid subjected to an acoustic field.

Reproducibility of the claimed tritium activity will also be necessary to verify whether tritium $\beta$ decay activity was produced via DD-fusion or any other means. It is also noteworthy in the usual liquid scintillation (LS) detection that $\beta$-rays emitted from radiocarbon with the end-point energy of $156 \mathrm{keV}$ might be piled on the $\beta$-ray spectrum for tritium with the end-point energy of $18 \mathrm{keV}$ if the $2 \beta$-decaying nuclides were simultaneously produced via neutron capture.

As an initial step toward investigating the possibility and verification of the claimed DD-fusion in cavitation experiments using d-acetone, we apply the accelerator mass spectrometry (AMS) technique to directly count ${ }^{14} \mathrm{C}$ atoms produced by the ${ }^{13} \mathrm{C}(\mathrm{n}, \gamma){ }^{14} \mathrm{C}$ reaction after $\mathrm{d}$-acetone is irradiated by energetic neutrons. But a combustion system to treat liquid acetone for the AMS measurement needs to be developed by taking into account the volatility of acetone, since solids are the main type of sample in AMS measurement.

In this article, we report a new combustion system in sample treatment to convert liquid or gas to $\mathrm{CO}_{2}$. The new combustion system uses high-purity $\mathrm{O}_{2}(99.999 \%)$ gas to combust liquid or gas samples. Since $\mathrm{O}_{2}$ gas reacts violently with liquid or gas samples, for safety reasons, we made the pressure of both the $\mathrm{O}_{2}$ gas and sample low and performed the combustion reaction. After the $\mathrm{CO}_{2}$ gas was made for a further reduction procedure (Lee et al. 2000; Vogel et al. 1987) and measurement, we used the AMS facility at Seoul National University (Kim et al. 2000).

\footnotetext{
${ }^{1}$ Corresponding author. Email: cslee@cau.ac.kr.
}

(C) 2004 by the Arizona Board of Regents on behalf of the University of Arizona Proceedings of the 18th International Radiocarbon Conference, edited by N Beavan Athfield and R J Sparks RADIOCARBON, Vol 46, Nr 1, 2004, p 141-145 


\section{DEVELOPMENT OF A COMBUSTION SYSTEM FOR LIQUID OR GAS SAMPLES}

\section{Conventional Combustion Method}

The combustion procedure allows one to convert the carbons of a sample to $\mathrm{CO}_{2}$ gas. Figure 1 shows the vacuum line of the conventional combustion system to treat solid samples, which recovers the $\mathrm{CO}_{2}$ gas after combustion (Lee et al. 2000). Chemically pretreated samples of 5-6 mg and Ag wires (each about $2 \mathrm{~cm}$ long and $0.2 \mathrm{~mm}$ thick) are inserted in a Vycor ${ }^{\circledR}$ tube, $5 \mathrm{~cm}$ in length and $6 \mathrm{~mm}$ in outer diameter. The Vycor tube and $1 \mathrm{~g}$ of $\mathrm{CuO}$ power are inserted in a vacuum-sealed quartz tube. The sealed tube was placed in a muffle furnace and combusted at a temperature of $850{ }^{\circ} \mathrm{C}$ for $2 \mathrm{hr}$. The $\mathrm{Ag}$ wire and $\mathrm{CuO}$ are baked at $850^{\circ} \mathrm{C}$ and $550^{\circ} \mathrm{C}$, respectively, for $2 \mathrm{hr}$ before being introduced into the combustion tube in order to release any absorbed contaminants from the ambient atmosphere. After combustion, the quartz tube is inserted in flexible bellows, followed by pumping of the vacuum line, then breaking of the tube to collect $\mathrm{CO}_{2}$. The released $\mathrm{CO}_{2}$ gas is separated from $\mathrm{H}_{2} \mathrm{O}$ by using dry ice/alcohol traps and cryogenically transported to the storage chamber for the further graphitization.

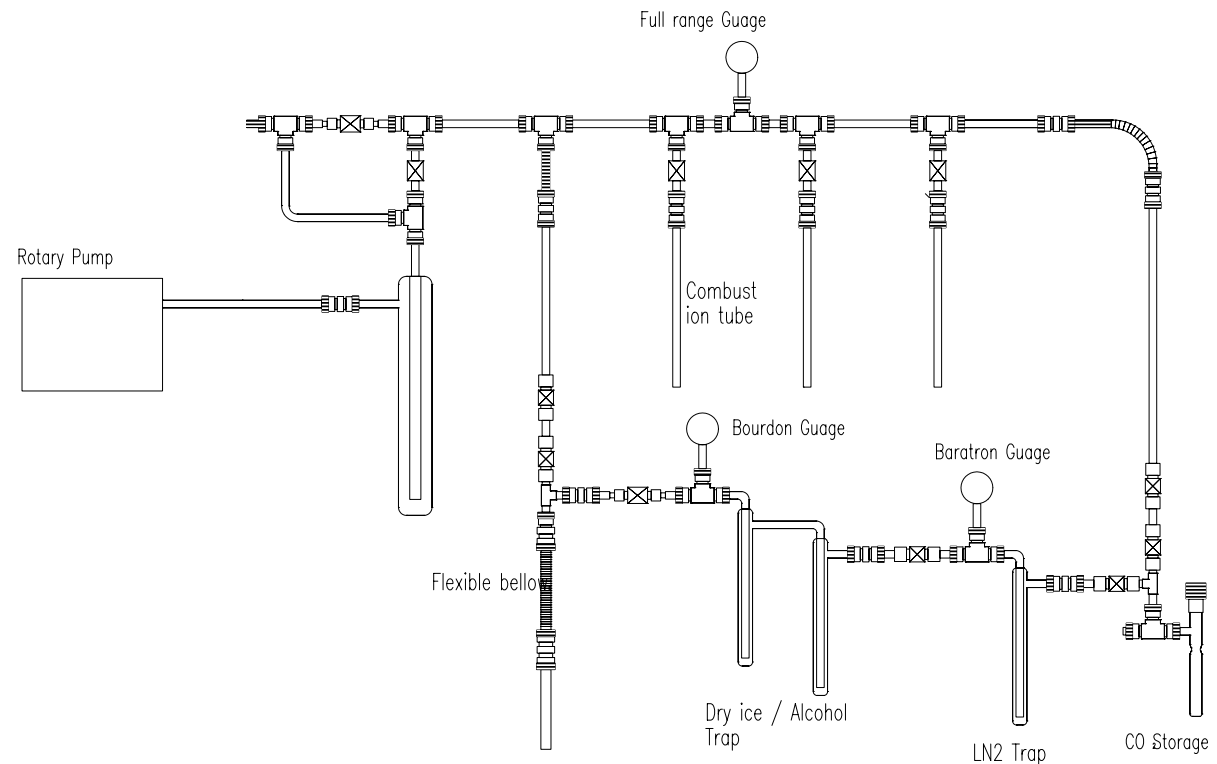

Figure 1 Schematic diagram of the conventional combustion system (Lee et al. 2000)

\section{New Combustion System for Liquid or Gas Samples}

A photograph of our combustion system for liquid or gas samples is shown in Figure 2 and its schematic diagram is given in Figure 3. Liquid samples of approximately $30-40 \mu \mathrm{L}$ are measured using a $100-\mu \mathrm{L}$ syringe, ensuring air is removed. The same apparatus can also be used for a gas sample by adding the gas storage chamber and a connection to the injection port. The reaction chamber consists of a quartz (or stainless steel) tube $17 \mathrm{~cm}$ in length and $1 / 2$ " outer diameter, and a Bourdon gauge with a range of $0-5 \mathrm{~atm}$. High-purity oxygen (99.999\%) is added into the system via the $\mathrm{O}_{2}$ injection port.

We tested the combustion system using deuterated acetone (acetone- $\mathrm{d}_{6}$, certified $100.0 \mathrm{~atm} \% \mathrm{D}$ ). The combustion system was evacuated, then high-purity oxygen (99.999\%) (600 torr) was injected 


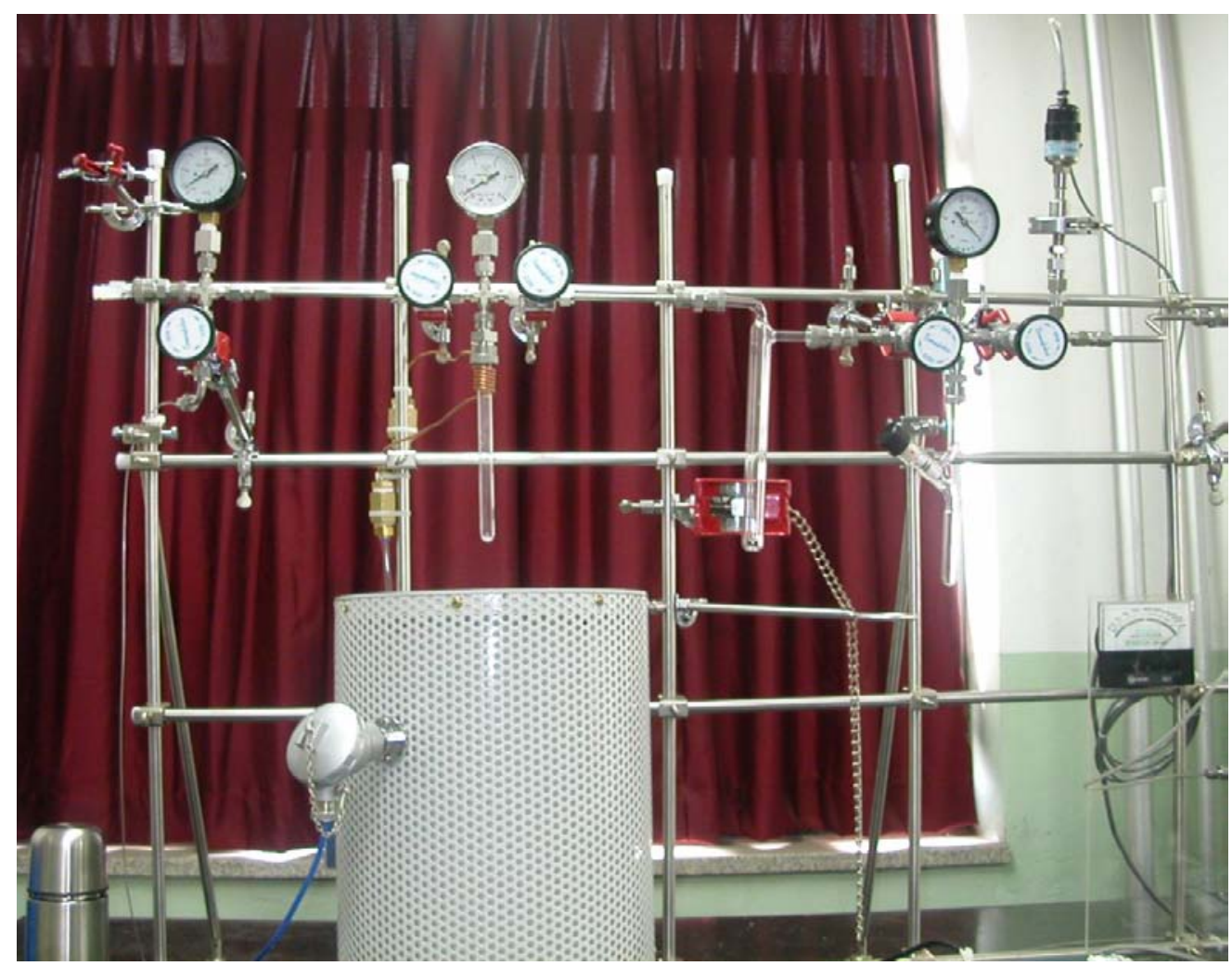

Figure 2 Photograph of the present combustion system for liquid and gas samples

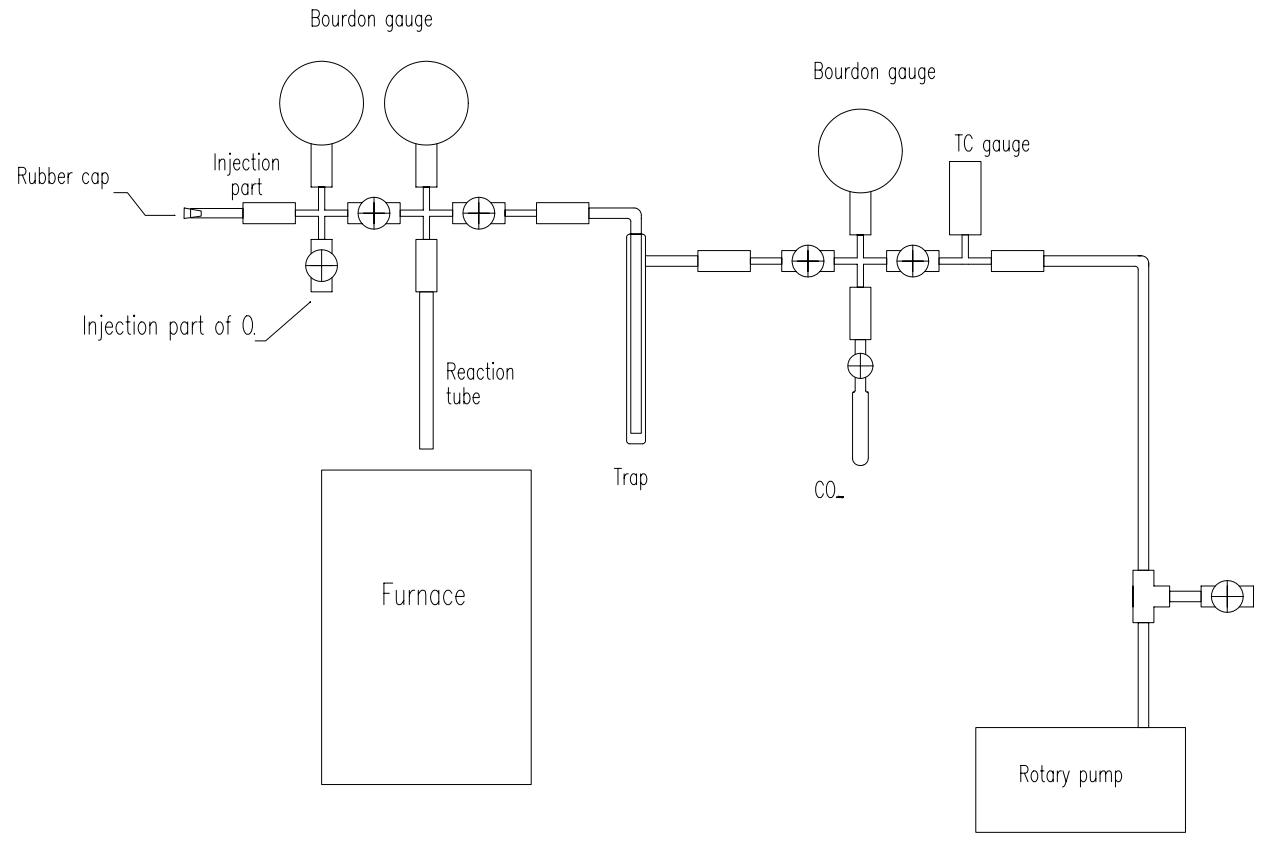

Figure 3 Schematic diagram of the present combustion line for liquid and gas samples 
into the reaction chamber. The sample $(10 \mu \mathrm{L})$ was injected via the rubber septum using a syringe. The d-acetone and oxygen were transferred to the reaction tube cryogenically, leaving 0.2 atm of $\mathrm{O}_{2}$ in the injection area. The furnace was heated to $800{ }^{\circ} \mathrm{C}$ to heat the reaction tube. A flash of light occurs when the combustion reaction takes place. If the pressure inside the reaction chamber (quartz) is greater than $1.5 \mathrm{~atm}$, it is possible that the reaction will break the reaction tube. Thus, we made the pressure inside the reaction chamber $1.5 \mathrm{~atm}$ and raised the furnace. After several seconds, a bright flash of light occurs and the reaction tube (quartz) breaks. To ensure safety, an acryl plate needs to be set in front of the reaction chamber and furnace, and the total pressure of the reaction chamber needs to be maintained around $1 \mathrm{~atm}$. After 5-10 $\mathrm{min}$, the furnace is lowered and the reaction chamber is allowed to cool. The reaction products are $\mathrm{CO}_{2}, \mathrm{O}_{2}, \mathrm{H}_{2} \mathrm{O}$, and $\mathrm{CO}$. $\mathrm{CO}_{2}$ is separated using dry ice/alcohol traps and a liquid nitrogen trap and transferred cryogenically to the storage chamber. The chamber has an approximate volume of $10 \mathrm{~mL}$ and the yield of carbon is then calculated from the measured pressure (typically around $0.13 \mathrm{~atm}$ ).

\section{RESULTS AND CONCLUSION}

Three deuterated acetone samples from the same sample with a volume of $1 \mathrm{~mL}$ were drawn to test the various combustion methods. Using our combustion system developed for liquid or gas samples, we made $\mathrm{CO}_{2}$ from the 3 deuterated acetone samples, followed by graphitization using a reduction system (Lee et al. 2000) housed at the AMS facility at Seoul National University (Kim et al. 2000). The ${ }^{14} \mathrm{C} /{ }^{12} \mathrm{C}$ ratios were measured at the AMS facility. Results of the measurement and the conditions of sample treatment are summarized in Tables 1 and 2.

Table 1 Conditions of sample treatment.

\begin{tabular}{|c|c|c|c|c|c|c|}
\hline \multirow[b]{2}{*}{$\begin{array}{l}\text { ID } \\
\mathrm{nr}\end{array}$} & \multirow[b]{2}{*}{$\begin{array}{l}\text { Used acetone } \\
\text { volume }(\mu \mathrm{L})\end{array}$} & \multirow[b]{2}{*}{$\begin{array}{l}\text { Type of } \\
\text { reaction tube }\end{array}$} & \multicolumn{2}{|c|}{ Pressure of the reaction chamber (atm) } & \multirow[b]{2}{*}{$\begin{array}{l}\text { Pressure of } \\
\text { produced } \mathrm{CO}_{2} \\
(\mu \mathrm{mol})\end{array}$} & \multirow[b]{2}{*}{$\begin{array}{l}\text { Content of } \\
\text { carbon in } \mathrm{CO}_{2} \\
(\mathrm{mg})\end{array}$} \\
\hline & & & Before reaction & After reaction & & \\
\hline 3 & 15 & Quartz & 1.4 & 1.5 & 95 & 1.1 \\
\hline 4 & 11 & Quartz & 0.8 & 0.7 & 47 & 0.6 \\
\hline 5 & 11 & Stainless steel & 1.25 & 0.7 & 65 & 0.8 \\
\hline
\end{tabular}

Table 2 Results of the AMS measurement.

\begin{tabular}{lllll}
\hline $\begin{array}{l}\text { ID } \\
\mathrm{nr}\end{array}$ & $\begin{array}{l}\text { Sample } \\
\text { code }\end{array}$ & $\begin{array}{l}\text { Type of } \\
\text { reaction tube }\end{array}$ & $\begin{array}{l}\delta^{13} \mathrm{C} \\
(\% \text {, PDB })\end{array}$ & $\mathrm{pMC}$ \\
\hline 3 & SNU 03-367 & Quartz & -34.1 & $0.6 \pm 0.1$ \\
4 & SNU 03-368 & Quartz & -43.8 & $2.6 \pm 0.4$ \\
5 & SNU 03-369 & Stainless steel & -27.4 & $0.8 \pm 0.1$ \\
\hline
\end{tabular}

From Table 2, one can see that the ${ }^{14} \mathrm{C} /{ }^{12} \mathrm{C}$ ratio of $\# 4$ is higher than those of $\# 3$ and $\# 5$ and the $\delta^{13} \mathrm{C}$ of \#4 is also lower than those of the others. Since we used deuterated acetone samples from the same sample but found that the ${ }^{14} \mathrm{C} /{ }^{12} \mathrm{C}$ ratio and the $\delta^{13} \mathrm{C}$ of $\# 4$ is different from the others, we conclude that \#4 might be slightly contaminated. Because the content of carbon which produced the $\mathrm{CO}_{2}$ of $\# 4$ is smaller, if \#4 is contaminated, the ${ }^{14} \mathrm{C} /{ }^{12} \mathrm{C}$ ratios and $\delta^{13} \mathrm{C}$ of $\# 4$ can change easily. However, in an effort to increase the content of carbon by raising the pressure of the reaction chamber higher than $1.5 \mathrm{~atm}$, the quartz reaction tube cracked. Therefore, the pressure of the reaction chamber should be maintained at $1-1.5 \mathrm{~atm}$. 
The stainless steel reaction tube (for example, \#5) may be more resistant to breaking, but it can introduce unwanted combustion of oxygen with the iron and carbon of stainless steel. As seen in Table 1, while the pressure of the reaction chamber for $\# 3$ and $\# 4$ after combustion is similar to that of the reaction chamber before combustion, the pressure of the reaction chamber for $\# 5$ after combustion is much lower than that of the reaction chamber before combustion. The authors believe that this phenomenon is mainly due to the combustion of oxygen with the iron of the tube. Since the resulting ${ }^{14} \mathrm{C} /{ }^{12} \mathrm{C}$ ratio of $\# 5$ (in Table 2) is low and similar to that of \#3, it could indicate that $\# 5$ is not contaminated. However, the possibility of an additional combustion of oxygen with carbon contained in the stainless steel cannot be ruled out.

It is recommended that the length of the quartz reaction tube is increased to $20-25 \mathrm{~cm}$ in order to treat a larger quantity of the sample, which will allow a lower pressure and make the experiment safer. Furthermore, the possibility of contamination and the unwanted combustion of oxygen with the iron and carbon that are contained in stainless steel can be avoided. Regarding the deuterated acetone with energetic neutrons, we recently conducted a neutron irradiation experiment by using fast neutrons produced in the ${ }^{9} \mathrm{Be}(\mathrm{p}, \mathrm{n})^{9} \mathrm{~B}$ induced by $20-\mathrm{MeV}$ protons. Neutrons measured with the time-of-flight technique (Kim et al. 1998) were shown to be in the energy range of 6-18 MeV, with the flux intensity maximum near $14 \mathrm{MeV}$. The irradiated deuterated acetone samples were combusted using the same combustion system developed for liquid or gas samples. AMS measurement of the ${ }^{14} \mathrm{C} /{ }^{12} \mathrm{C}$ ratios for the samples is underway at the AMS facility of Seoul National University.

\section{ACKNOWLEDGEMENTS}

This work was supported by a grant (R01-2003-000-10016-0) from the Korea Science and Engineering Foundation.

\section{REFERENCES}

Kim JC, Lee CH, Kim IC, Park JH, Kang J, Cheoun MK, Kim YD, Moon CB. 2000. A new AMS facility in Korea. Nuclear Instruments and Methods in Physics Research B 172:13-7.

Kim JH, Bhang H, Ha JH, Kim JC, Kim MJ, Kim YD, Park H, Chai JS, Kim YS, Lee HY, Shin SA, Huh JY, Lee CS, Lee JH. 1998. A measurement of monoenergetic neutrons from ${ }^{9} \mathrm{Be}(\mathrm{p}, \mathrm{n}){ }^{9} \mathrm{~B}$. Journal of the Korean Physical Society 32(4):462-7.

Lee C, Kim JC, Park JH, Kim IC, Kang J, Cheoun MK, Choi SY, Kim YD, Moon CB. 2000. Progress in sample preparation system for the Seoul National University AMS facility. Nuclear Instruments and Methods in Physics Research B 172:454-7.

Shapira D, Saltmarsh M. 2002. Nuclear fusion in collaps- ing bubbles-Is it there? An attempt to repeat the observation of nuclear emissions from sonoluminescence. Physical Review Letters 89(10):104302-1104302-4.

Taleyarkhan RP, West CD, Cho JS, Lahey RT Jr, Nigmatulin RI, Block RC. 2002. Evidence for nuclear emissions during acoustic cavitation. Science 295: 1868-73.

Vogel JS, Southon JR, Nelson DE. 1987. Catalyst and binder effects in the use of filamentous graphite for AMS. In: Gove HE, Litherland AE, Elmore D, editors. Proceedings of the 4th International Symposium on Accelerator Mass Spectrometry. Nuclear Instruments and Methods in Physics Research B 29:50-6. 